\title{
LINGỨÍSTICA, IDIOMÁTICA Y ESPAÑOL DE AMÉRICA
}

José Joaquín Montes G. Instituto Caro y Cuervo, Bogotá

Esta nota no pretende ninguna originalidad particular. Intenta simplemente hacer un recuento de pronunciamientos anteriores sobre el tema lingüistica-idiomática, buscar un poco más de claridad al respecto, precisar el concepto de lo idiomático en un aspecto relativamente nuevo y aplicar esto a ciertos problemas del español de América.

\section{Publicaciones anteriores.}

De tiempo atrás, pero particularmente desde "Habla, lengua e idioma" ", había planteado la norma como tradicionalización o historización de la convención y el idioma (lengua histórica) como el conjunto articulado de normas $^{2}$; también planteo allí (pág. 12) que la norma, "fenómeno esencialmente social e histórico en cuanto tradición, es el eslabón necesario que une la lengua-convención, el sistema, con el 'idioma' en cuanto tradición social histórica $\mathrm{y}$, por consiguiente, la 'lingüística interna' y la 'lingüística externa' " y enfatizo la conveniencia de separar lengua 'convención interindividual o sistema de convenciones' de idioma 'lengua histórica'. En Dialectología general e hispanoamericana ${ }^{3}$, repito lo de la norma como de naturaleza eminentemente socio-histórica y como conformadora de los idiomas (págs. 28-29). En varias de las reseñas publicadas por mi en $B I C C$ en los últimos años he recalcado la conveniencia de utilizar de modo consecuente politica idiomá-

1 BICC, XXXVIII, 1983, págs. 325.39.

2 Art. cit., págs. 5-7 de la separata.

3." ed., Bogotá, ICC, 1987. 
tica ${ }^{4}$ en vez de politica lingüística por cuanto tal política se refiere siempre al aspecto histórico-social de la lengua y no a fenómenos de su estructura o naturaleza interna. Sobre igual tema insiste una noticula publicada en la revista Contextos $^{5}$. En la revista Alfa $^{6}$, he llamado la atención sobre algo que ya había expresado en mis obras de dialectología: que el problema de la delimitación de los idiomas no puede resolverse dentro de la pura sistémica (lingüistica interna), sino desde la idiomática o estudio de las relaciones de los entes históricos en que se articula el hablar humano y que por tanto este problema es más sociopolítico que sistémico o glótico.

En sintesis, todos los planteamientos a que me he referido tienden a renovar la distinción saussureana de lingüistica interna (= sistémica, glotología) y lingüística externa (idiomática) sobre nuevas bases.

\section{II. ¿Español “de” América o español “en” América?}

Adelantando sobre algo que espero quede mejor argumentado más adelante, recordaré algunas opiniones mias sobre el tema. En la revista Alfa $^{7}$, apareció el texto de una conferencia que dicté en la Universidad de Panamá en febrero de 1986; alli, bajo el subtítulo "Una cuestión previa", decía :

Cuando hablamos de «español de América» no es raro que alguien corrija «español en América», lo que suele ocurrir particularmente con nacionales españoles. ¿Por qué esto? ¿Qué envuelve el cambio de preposición? Evidentemente, el de posesivo da a la expresión el sentido de algo propio de América, mientras que el en, con su carácter simplemente locativo, solo conlleva la presencia en un lugar dado sin que implique ningún vínculo de dependencia u origen con el lugar. Pero como el español de América no es un simple trasplante de algo ajeno sino entidad que ha crecido con las savias del Nuevo continente, decimos y diremos «espeñol de América» para relievar su definitiva originalidad americana.

Y citando a Cuervo daba algunas razones de mi posición consistentes, en esencia, en la adaptación al medio americano que el espafiol comenzó a experimentar desde el momento mismo de la llegada de los europeos.

En la reseña de un interesante libro de José G. Moreno de Alba (ver

\footnotetext{
- Por ej., sobre José G. Moreno de Alba, El español en América, en BICC, XLV-1, 1990, págs. 195-97; sobre H. Obregón, Hacia la planificación del español de Venezuela y la determinación de una politica lingüistica: BICC, XXXIX, 1984, págs. 353-54; Fundamentos lingǘsticos para una política idiomática en la comunidad bispanobablante: BICC, XXXVIII, 1983-84, págs. 1632-33.

s Medellín, núm. 6, págs. 139-43.

- Sao Paulo, núm. 33 (1989), págs. 129-35.

7 Panamá, núm. 7, segunda época, julio de 1988.
} 
nota 4) tuve oportunidad de expresar mi desacuerdo con la posición de este distinguido hispanista que usa y defiende explícitamente "español en América"; y en el Primer Taller Internacional sobre el Español en América (La Habana, 1989) defendi también mi posición frente a los colegas cubanos que creen se debe hablar de "español en América".

\section{LA IDIOMÁTICA Y EL IDIOMA COMO LUGAR DE LOS VALORES LIGADOS A LA LENGUA.}

Que los valores son algo esencialmente humano que solo se concibe y surge en la sociedad de los hombres, parece algo evidente que no requiere demostración; y parece también indudable que una de las propiedades básicas de los valores es la de "ser irracionales, esto es, incognoscibles por la razón y solo aprehensibles en una experiencia emotiva personal y concreta" 8 . En cuanto irracional y emotivo el valor puede considerarse, pues, la contraparte del conocimiento racional en el que no se acepta y antes se rechaza el elemento emotivo.

Tampoco parece caber duda razonable de que el lenguaje y la lengua (las lenguas), además de instrumentos esenciales de la sociedad humana, son también, y quizá por ello mismo, valores que pueden concitar y concitan de hecho la adhesión emotiva y aun apasionada de los hombres.

Ahora bien, es cierto que el de la constitución de una lengua común es también, y en primer lugar, un problema politico y que la lengua de una comunidad, como primer rasgo individualizador de ésta, puede ser objeto de pasión polf́tica 9 .

En mi obra Dialectología y geografía lingüistica ${ }^{10}$ cité diversos casos de pugnas apasionadas de comunidades alrededor de la lengua, mejor, del idioma; y el mundo moderno es un hervidero de problemas por la reivindicación por grupos minoritarios dentro de un Estado de sus idiomas propios (vascos, catalanes, gallegos, etc., en España, francófonos del Canadá, comunidades indígenas de América, etc.).

Entonces, si la norma es tradición, lo que quiere decir historia, y son las normas las que constituyen los idiomas ("El idioma, conjunto articulado de normas", titulé un apartado de mi citado "Habla, lengua e idioma"), que las comunidades humanas asumen como propios (ì்

- Enciclopedia Larousse.

- E. Coseriu, «El gallego y sus problemas» (LEA, IX, 1987, págs. 127-38), pág. 127.

10 Bogotá, ICC, 1970, pág. 23, nota 11; también en Dialectología general e bispanoamericana, 2." ed., Bogotá, 1987, págs. 53-54, nota 32. 
identidad grupal, podemos decir que el valor que surge en la conciencia del individuo ligado al fenómeno del lenguaje (idioma):

a) No tiene como contenido el instrumento lingüistico en si (la estructura y sus elementos) sino el hecho de que tal instrumento sea signo de identidad grupal y portador de la tradición comunitaria.

b) Las normas como tradicionalización o historización de las convenciones lingüísticas representan el ingreso del hecho lingüístico en el mundo de la sociedad histórica y, por lo tanto, de los valores.

c) Esto significa que la idiomática, como estudio de las normas lingüísticas y sus relaciones en el más amplio sentido posible y la dialectología como intraidiomática (relaciones de las normas al interior de un sistema autónomo), están inmersas en el mundo de los valores (idiomáticos) y no pueden ignorarlos en sus actividades. $\mathrm{Y}$ que pretender limitarlas al análisis del instrumento lingüístico separado de su componente sociohistórico, valorativo, es sacarlas de su campo específico y convertirlas en algo ajeno a su esencia, en una especie de paleontología, pues los elementos del sistema en su funcionamiento real no están aislados de los valores históricos.

d) El idioma o lengua histórica puede concebirse, pues, como entidad de doble faz, de modo similar a como entendia Saussure el signo lingüístico: una faz es la del puro instrumento comunicativo, la estructura con sus elementos y relaciones, faz a la que el estructuralismo pretendió limitar el estudio, y otra faz es la que refleja el vivir histórico de los pueblos, sus tradiciones, concretadas en las normas y sus interrelaciones ${ }^{11}$.

\section{El español de America y su identidad.}

Tras las consideraciones generales que quedan esbozadas podemos examinar algunos problemas específicos del español de América:

\section{Español de América, español en América.}

Uno de los textos que pueden considerarse clásicos como argumento en pro del sintagma "español de América", es el de Cuervo, que he citado en varios lugares.

11 Esto ya había sido expresado en términos ligeramente diferentes por E. Coseriu en «Los conceptos de 'dialecto', 'nivel' y 'estilo de lengua' y el sentido propio de la dialectologla», en Lingilfstica española actual, III, 1981, 1-31 [pero el artículo fue escrito originalmente en 1958] al hablar de la arquitectura, como correlato de la estructura y como correspondiente a la lingüfstica externa (art. cit., pág. 22). 
Puestos los conquistadores en un mundo verdaderamente nuevo, cual debió de parecerles aquel en que ni el hombre ni la naturaleza se asemejaban a los de Europa, padeció la lengua otra especie de dislocación, a modo de transportación musical, para acomodarse a designar objetos desconocidos: en la zona tórrida, por ejemplo, el invierno y el verano no podfan ser el tiempo de las nieves y de los calores, y se convirtieron en el de las lluvias y el de la seca ${ }^{12}$.

Abundando en el pronunciamiento de Cuervo, he expresado que la adaptación del español al medio americano ha avanzado desde la época en que escribía Cuervo, como puede comprobarse con el ALEC, en el que invierno aparece no solo como 'época de lluvias' sino como 'aguacero' ${ }^{13}$.

$\mathrm{Y}$ en otros trabajos he mostrado algunas de las numerosas expresiones que se constituyen con hase en elementos de la naturaleza americana y que conforman así un americanismo radical, digamos de motivación americana ${ }^{14}$.

Los hechos que acaban de citarse hacen referencia a los cambios en el instrumento lingüístico (langue). Pero también es pertinente para el caso la actitud (valoración) de los hablantes americanos desde los primeros tiempos del trasplante del español en América :

Dejando de lado ahora la adhesión de los primeros españoles cmigrados a la tierra descubierta /.../ puede suponerse con fundamento que ya en la primera generación de criollos, es decir, de hijos de españoles nacidos en el nuevo continente, se generó un sentimiento de pertenencia, cuyo desarrollo culminó en la conciencia de la identidad criolla 15 .

Creo, pues, que la justificación de "español de América" se da desde ambas perspectivas: desde los elementos del sistema lingüístico y desde las actitudes o valoraciones que los hablantes asumen en relación con su idioma.

\section{2. ¿Puede hablarse de español de América?}

En un trabajo reciente, "El español de América en el siglo xxi" ${ }^{16}$, tuve ocasión de referirme a la polémica sobre si es legítimo postular 'español de América' como entidad separable dentro del diasistema español ; esta polémica parte de o se reaviva en los últimos años con el breve artículo de

12 En Obras, II, ICC, 1954, págs. 546-47.

13 ALEC, I, 118.

14 Ver J. J. Montes, «Medio físico y cambio léxico en voces del español de Colombia», en Pbilologica Hispaniensia in honorem Manuel Alvar, I, Gredos, Madrid, 1983, págs. 459-69.

1s J. L. Rivarola, La formación lingǘstica de Hispanoamérica, Lima, 1990, págs. 22-23.

16 En El español de América hacia el siglo XXI, Bogotá, ICC, 1991, págs. 130-43. 
J. P. Rona “¿Qué es un americanismo?” 17, que, como se sabe, niega la existencia del americanismo como rasgo común a toda América y ausente de toda España. En mi artículo de 1991 antes citado, me permití dudar de la ausencia total de americanismos en el sentido postulado por Rona y agregué que la estructura externa también justifica $y$ ha justificado siempre el hablar de entidades idiomáticas. Pero en realidad la tesis de Rona ha sido ya brillantemente refutada por G. L. Guitarte:

Teniendo presente [ 'estos?] hechos, comprendemos que cuando la «dialectología hispanoamericana tradicional» juzgaba las formas populares americanas como «desviaciones» de la norma española (peninsular) no hacía más que conservar una idea de la lengua standard diferente de la que tenemos en la actualidad. Me parece importante señalar el hecho porque creo que en este punto la crítica que puede hacerse a la antigua dialectología no corresponde al plano de la teoría lingüística, sino al de la vida práctica, al de la historia /.../. El problema no pertenece al plano teórico, donde existen la verdad y el error. Uno podrá ser partidario de las variedades nacionales del standard español, porque le parece justo que se reflejen en él las peculiaridades del país o, simplemente, porque le parece inútil intentar modificar una situación ya consolidada; los partidarios del standard español serán acusados de anacrónicos o, más truculentamente, de carecer de patriotismo: en última instancia se trata de conductas, puestas en marcha por un acto de voluntad que defiende una determinada orientación ${ }^{18}$.

y también por Rivarola:

Finalizaré recalcando que los planteamientos anteriores se atienen a una concepción de las lenguas que privilegia su condición de entidades históricas sustentadas en las colectividades humanas que las emplean, las desarrollan, reflexionan sobre ellas, las integran a su conciencia cultural, las convierten en señales de identidad. En este sentido el español de América no requiere otra justificación que la que se deriva de esta concepción; postular su inexistencia -como se ha hecho- sobre la base de argumentos geográfico-lingüísticos $/ \ldots /$ es situarse en otro orden de ideas, el de un determinado tipo de abstracción que, aparte de su propia historicidad inherente, no tiene el modo de existencia y realidad que tienen los objetos históricos a los que se ha contrafdo el presente trabajo ${ }^{19}$.

\section{El inmanentismo autonomista y la negación del 'español de América'.}

De los planteamientos anteriores resulta claro, creo, que la negación de la legitimidad del concepto de 'español de América' como entidad con exis-

17 En El Simposio de México, México, UNAM, 1965, págs. 135-48.

18 G. L. Guitarte, «Dialecto, español de América e historia en Coseriu», en Energeia und Ergon, Bd. II, Das sprachtheoretische Denken Eugenio Coserius in der Diskussion, Gunter Narr Verlag, Tübingen, s. f., pág. 489.

io Rivarola, op. cit., págss. 27-28. 
tencia propia procede de la concepción de la lengua como el puro sistema (=langue) aislado de sus determinantes histórico-sociales y consecuencialmente axiológicos, concepción evidentemente propia del estructuralismo.

Pero como lo he sostenido de tiempo atrás (Dialectología y geografía lingüistica, Dialectología general e hispanoamericana) remitiéndome a conceptos de otros estudiosos, el problema lengua-dialecto (y agregaría ahora, el problema de los idiomas o agrupaciones históricas del hablar) no puede resolverse desde la pura lingüística interna sino desde la idiomática como estudio de las normas (históricas), sus interrelaciones y los valores que conllevan. Tanto o más que una suma de elementos comunicativos el español de América es un hecho de conciencia y un conjunto de valores en la mente de los americanos. Y puede aceptarse el planteamiento de Rivarola según el cual en la valoración americana del idioma español se percibe el anhelo de una patria hispanoamericana ${ }^{20}$, cierto deseo de una unidad espiritual (y política) fundada en el idioma común.

\section{Conclusiones.}

Como conclusiones de estos breves planteamientos podría proponerse:

1. La norma es la historización de la convención, el ingreso de la lengua (langue $=$ lengua sistema) en el suceder histórico-valorativo.

2. Esto implica que el idioma, los idiomas o formas históricas del hablar, son siempre entidades bifácicas: sistemas comunicativos y entes históricos objeto de valores.

3. No puede, pues, negarse la existencia de una entidad idiomática, y concretamente del español de América, con base en una supuesta (y discutible) falta de elementos diferenciadores específicos.

\section{Abreviaturas.}

ALEC $=$ Atlas lingüistico-etnográfico de Colombia. Bogotá, ICC, 1981-1983. 6 vols.

BICC = Boletín del Instituto Caro y Cuervo. Bogotá.

ICC = Instituto Caro y Cuervo. Bogotá.

LEA = Lingüística española actual. Madrid.

\footnotetext{
20 «En el caso de América se trata, para el efecto, de un concepto extendido de nación, que, como se ha visto, tiene una plena justificación histórico-ideológica por lo menos desde fines del siglo xvin» (Rivarola, op. cit., pág. 27).
} 